Krobová, T., Moravec, O., \& Švelch, J. (2015). Dressing Commander Shepard in pink: Queer playing in a heteronormative game culture. Cyberpsychology: Journal of Psychosocial Research on Cyberspace, 9(3), article 3. doi: $10.5817 /$ CP2015-3-3

\title{
Dressing Commander Shepard in pink: Queer playing in a heteronormative game culture
}

\author{
Tereza Krobová ${ }^{1}$, Ondřej Moravec ${ }^{2}$, Jaroslav Švelch ${ }^{3}$ \\ ${ }^{1,3}$ Faculty of Social Sciences, Charles University in Prague, Czech Republic \\ ${ }^{2}$ Independent scholar
}

\begin{abstract}
This article explores the strategies of queer playing of video games and their relationship to the heteronormative game culture. Its premise is that most video games are, either implicitly or explicitly, heteronormative and the inscribed player of such games is in the majority of cases a heterosexual male. In order to achieve the same level of identification with an avatar and to enjoy a similar gameplay experience as the heterosexual player, the LGBT player may have to deploy various strategies to challenge the game and work around it, or to find the LGBT content which some more progressive games offer. The study is based on in-depth qualitative interviews with six players ( 5 males and 1 female) who identified themselves both as homosexual and as players of the Mass Effect or Dragon Age series, games that include several opportunities to initiate same-sex romance. We have identified three different queer playing strategies: imaginative play (queer reading of unspecified or heterosexual characters), stylized performance (the use of gay stereotypes to mark one as queer) and role-playing of a LGBT character. However, players do not seek sexuality in games to the same extent as they do in film or TV, and they tend to use these strategies, and especially the latter two, reluctantly or with reservations. These reservations may be linked to our finding that LGBT players consider their gay (or lesbian) identities disconnected from their identities as players or gamers. This can be explained by the mutual exclusivity of gay communities and the heteronormative game culture.
\end{abstract}

Keywords: video games, LGBT community, heteronormativity, queer playing, gender

\section{Introduction}

As Adrienne Shaw pointed out in her pioneering article about LGBT content in video games, most video games are, either implicitly or explicitly, heteronormative (Shaw, 2009). Their narratives rarely include non-heterosexual characters and they usually presume a straight male consumer. While the game industry tends to overlook its LGBT audience, some gaming communities are even seen as homophobic, for example due to their extensive use of words like "gay" or "fag" to describe weaker players (Sliwinski, 2007; Shaw, 2009). Nevertheless, conversations about LGBT players and content have been going on both in the industry and in academia. Some of the activity revolves around alternative and indie productions - such as the work of transgender game designer Anna Anthropy (2012b) - but several mainstream game developers ${ }^{1}$ have also acknowledged their LGBT audiences and purposefully introduced LGBT characters and themes into their games.

One of the most outspoken proponents of the inclusion of LGBT content into mainstream games has been David Gaider, senior writer at BioWare, a Canadian studio which specializes in narrative-driven roleplaying games (RPGs) which usually contain optional romance subplots. In both Mass Effect and Dragon Age franchises, BioWare has been including the option for same-sex romances as well as player or nonplayer characters who have other than straight sexualities. In his talk Sexism and Sexuality in Games given at the Game Developers Conference in 2013, Gaider recounts the origin of same-sex romances in 
BioWare games, admitting that developers originally "assumed that the player base would never accept that". Later, they realized that by writing about romance and sex, they were inevitably saying something "about what was acceptable and what was normal, and who we thought our audience was. [...] We said that by the virtue of what we included as well as what we didn't include." Since Jade Empire (BioWare, 2005), BioWare have been including same-sex romances in all of their major titles. Among the most memorable were the potential gay romances of the main player character (given that he is male) with crew member Kaidan Alenko in Mass Effect 3 (BioWare, 2010) and with the mage Anders in Dragon Age II (BioWare, 2011). Gaider stops short of saying that BioWare promotes a liberal pro-LGBT agenda, instead arguing that "the industry could be less dis-inviting of players who would otherwise be paying customers". Although these efforts have been routinely met by homophobic backlash from a vocal minority of players, Gaider (2013) stresses that the inclusion of LGBT content in their titles has never hurt their sales. Bioware's goal, as interpreted by Gaider, is therefore to please their diverse audience by writing diverse sexualities into their games.

While the reasons for introducing LGBT content may vary, they usually stem from the developers' assumptions about their target audiences (Shaw, 2009). Studios tend to assess the value of offering more sexual diversity by sales figures or by reactions pulled from online forums (Gaider, 2013; Greer, 2013). However, we have little knowledge of how LGBT players actually experience these games; how they perform and interpret on-screen action. Existing scholarship on LGBT issues in video games has drawn from mostly press coverage and developers' statements, or textual analysis and introspective techniques. Shaw, for example, explains the invisibility of LGBT communities is games by the heteronormative tendencies of the male-dominated game industry (Shaw, 2009). Greer, on the other hand, explores the complexity of designing games for a queer audiences (Greer, 2013). Although these articles make valuable arguments about the structural and discursive obstacles and possibilities for the inclusion of LGBT content, they do not focus on player experience. The lack of reception studies may create a false impression of a homogeneous LGBT audience. This article focuses primarily on the LGBT audience and aims to show the variety and diversity of LGBT experiences and strategies, as well as their relationship to the heteronormative game culture. Given the prominence of BioWare titles in the discussion about LGBT content, we will narrow down our focus on the players of the Dragon Age and Mass Effect series, the former of which is a fantasy-themed RPG series, whereas the latter contains an epic science fiction story.

First, we will set the scene by providing an overview of the relationship between LGBT players and the generally heteronormative game culture. We will follow with a theoretical examination of the potential for queer reading and playing of video games. We define queer not only as an umbrella label for the LGBT community, but also as a strategy - a radical questioning of social and cultural norms and notions of gender (Sullivan, 2003). In this sense, this deconstructive concept cannot be described, as it has no fundamental logic or consistent set of characteristic (Jagose, 1996, p. 96). "[Queer] demarcates not a positivity but a positionality vis-a-vis the normative." (Halperin, 1997, p. 62)

The empirical part of the article will address player histories and attitudes towards games and game communities before investigating the queer playing strategies they pursue, as well as their evaluation of LGBT content in the Dragon Age and Mass Effect series.

\section{LGBT Player and the Heteronormative Game Culture}

Sexuality is an integral part of video games, as they explicitly or implicitly represent the gender system and social norms (Consalvo, 2003). The fact that most games are heteronormative is neither a coincidence, nor a random choice. According to Adrienne Rich (2004), we have to think about heterosexuality as a political institution, which is involved (consciously or not) in maintaining the status quo. Discursive power of heteronormativity lies primarily in the fact that heterosexuality is almost invisible; it is defined as a default version of sexuality. Heterosexuality, contrary to homosexuality, does not need any physical evidence, it is defined as a "regular" part of life. We can recognize it in everyday communication, where the automatic assumption of heterosexual orientation creates the necessity of the declarative coming out, which can be understood as a confession. A similar pattern can be observed in media content, video games included.

In the majority of cases, the implied reader of video games is a white heterosexual male player. That may stem from the fact that most game developers are heterosexual men - the International Game Developers Assocation's 2014 survey shows that majority of the developers (86\%) identify themselves as heterosexual and $76 \%$ are men (IGDA, 2014). We can assume that these male developers just create games for themselves (Cassell \& Jenkins, 2000), although their actual audiences are much more heterogeneous. In video games, heteronormativity manifests on two levels - within their content (including fiction and rule systems), and in the performance of gameplay. 
At the level of content, a video game can be understood as a cultural artifact which tends to reproduce broader patterns of the gender system. Therefore, the fictional content of video games contains stereotypical romances within their plots, often marked with a vivid hierarchization of gender relations. In most cases, a player controls the male character, and the female character is relegated to the role of socalled "damsel in distress" (Vorderer \& Bryant, 2012). But heterosexualization can be even more implicit it can be simply inscribed into the game mechanics and the rules of the games. Consalvo (2003) notes that the untold heterosexual narrative is the motivation of many game characters - the "princess" (abstract or real, for example in Donkey Kong (Nintendo, 1981)) can then be understood as any final reward for the player.

At the level of performance, the environment and the plot of role-playing games are mainly experienced through the avatar. The avatar can be defined as a human-controlled virtual construct which serves as a connection between other people or characters (Berger, 2002). Avatar is not just a game character, but also the players themselves and their identities, their own imperfect bodies expanded or exceeded within the fictional world (Klevjer, 2006). "Through avatars, users embody themselves and make real their engagement with a virtual world" (Taylor, 2002, p. 40). Avatars, in this sense, are the access points for creation of a player identity, gender identity included.

Despite the fact that the players have a degree of control over them, avatars are also subject to the rules of heteronormative representation. Both male and female characters are predominantly designed by men, and moreover by heterosexual men. Therefore, women are designed to be attractive to watch, while male characters are attractive to play (Cassell \& Jenkins, 2000). Female bodies are often oversexualized and scantily and dressed (Kennedy, 2002), and therefore made ready for the male gaze (Mulvey, 1989). The powerful and muscular male character, on the other hand, represents the concept of hegemonic masculinity (Connell, 2005), the normative pattern of practice which embodies the most honored way of being a man. Hegemonic masculinity "require[s] all other men to position themselves in relation to it, and it ideologically legitimate[s] the global subordination of women to men" (Connell, 2005, p. 832).

Representation of the LGBT community, if it ever occurs, is under constant pressure to correspond to heteronormative patterns, and also incorporates conventions inherited from media narratives. Although developers may try to make the game world more heterogeneous with the creation of LGBT characters, these can be mere caricatures of homosexuality, as we will show later. Several games have tackled subjects related to LGBT communities, such as sex change in dys4ia (2012) or coming out in Gone Home (2013). However, these games have not reached the impact that "queer cinema" has had on film (Benshoff \& Griffin, 2004; Shaw, 2009).

The push to include LGBT content is being undermined by the fact that video game culture is generally not recognized as a part of gay culture (Taylor, 2002). Some gay players explicitly identify as "gaymers" (gay and gamer) and gather on dedicated discussion forums (Shaw, 2009); according to Cassell and Jenkins (2000), queer playing can even be seen as one of the first impulses for a real coming-out. But as Greer points out, LGBT players do not necessarily feel the need to "play queer" (Greer 2013). One has to ask, moreover, whether LGBT players even want to be appealed to as a target audience. Creating games specifically for gay players might result in their ghettoization, which has to some extent happened with "girl gamers". As Taylor (2002) notes, "like girl gamers before them, the homosexual market for games is being appealed to as gays, not as gamers" (p. 238).

Therefore, in order for more video games with queer characters to be created, the existence of motivated producers (who identify themselves as homosexuals or at least not homophobic) is deemed especially important (Shaw, 2009). They must also, like David Gaider, believe that there is an audience for this content (Taylor, 2002). So far, there has been no consensus whether developers should create queer emancipatory games and create a video game alternative of "queer cinema", or to create games "for everyone", with (optional) queer characters or mechanics included.

\section{Potential for Queer Playing: Affordances and Strategies}

In this section, we present a theoretical framework that will allow us to outline and categorize a number of hypothetical queer uses of video games, which will be later compared to our empirical findings. We shall build on existing literature about gender and queer elements in both the game as an artifact, and in player practice.

In the context of video games, the concept of queer playing can describe a variety of uses, identities and identifications. In this article, we will focus on a specific subset of uses, identities and identifications - 
those which are performed by LGBT players who challenge heteronormative game culture by reading or performing in-game characters as gays or lesbians. These are not the only "queer" uses of games, but the contrast with heteronormativity makes them illustrative of "queer" engagement with games in general.

Regarding the game as a computational artifact, the potential for queer engagement is always constrained by the developers' design choices. Greer (2013) suggests using the concept of affordances ${ }^{2}$ to describe the ways in which a particular game title allows for expressions of sexuality: "While players may remain free to engage in their own imaginative play - external to the game text by ascribing sexuality to game characters and exchanges where it is not explicitly indicated by the game itself - the quality of affordance permits a more analytical account of the relationship between designed content and the 'performative' qualities of game play" (p. 8).

At the very basic level, we can classify games based on the degree to which they contain (or "afford") the options to engage the avatar in explicitly queer romantic and sexual behavior. ${ }^{3}$ For example, the customizable player character in Dragon Age: Origins (BioWare, 2009) can be either male or female, based on the player's choice. Later on, he or she recruits other party members. If the player opts for a male character, the avatar can engage in a sexual relationship with two female party members or one male companion (Zevran), who is portrayed as bisexual; the character of Leliana can be similarly romanced by both men and women. The possibility of same-sex romance is therefore acknowledged by the game's rules. In Mass Effect (BioWare, 2007) and Mass Effect 2, one can also choose to play as a male or female Commander Shepard. However, these two games allow only for lesbian relationships between a female Shepard and another female love interest. ${ }^{4}$ This means that if the player opts to project his gay man identity into the player character, he is left without romance options, and therefore unable to declare his sexuality within the game's narrative. Mass Effect 3 (BioWare, 2012), on the other hand, allows for both gay and lesbian relationships - including a romance between a male Shepard and the soldier Kaidan Alenko, who had appeared in all previous Mass Effect games without being explicitly portrayed as a gay man.

What is in the game is not the only thing that matters. The player can use the game queerly, both on the level of interpretation and performance. First, there are potential "oppositional" (Hall, 1980), or in our case queer, readings of every character. Even if the characters' homosexuality is not explicitly declared in the game and there is no evidence of queerness in the narrative (in stereotypical depiction, gestures or action), the queer player can take advantage of the "blind spots" - unclear aspects of a character or the polysemy of the narrative - and fill them in with his or her own queer interpretations. Such a player engages in what Greer has called "imaginative play" (Greer, 2013). Queer readings can have various degrees of freedom related to the magnitude of the effort which is necessary to expend - on the one hand, we can speak about a strictly and exclusively heterosexual character, a queer reading of whom requires considerable effort, on the other hand, we encounter an implicitly homosexual character readily open to a queer reading. Queer reading, as Taylor (2002) suggests, may allow players to compensate for a lack of representation of LGBT themes, but that does not preclude the demand for more representation.

Video games also provide spaces in which players can perform and experiment with genders and identities. In this sense, video games can be seen as a literal manifestation of the concept of cyborg (Haraway, 2013). Video game avatars can be seen as hybrids of human (the player) and machine (the computer acting per the instructions of the game program), leaving us unable to distinguish where either part ends and the other begins. Players may perform gender in the fictional worlds as they "do" gender in social reality (Butler, 1990), but without the immediate real-life consequences. This allows for destabilization and subversion of gender stereotypes, which was labelled genderfuck by Reich (1992). In the simulated world of the game, the politics of identity ends and the politics of performance in Butlerian sense begins. To quote Reich (1992), "we are not defined by who we are but what we do" (p. 217). This holds especially true in games like Dragon Age and Mass Effect, in which the player character is never clearly defined as either hetero- or homosexual - he or she can only make straight or queer choices.

Vorderer and Bryant (2012) argue that "to break loose from gender (if ever possible) in online environment would be to become emancipated from the norms controlling the real-life gender and to enjoy, for a moment, the freedom of the opposite sex" (p. 301). As their research highlights (Rutter \& Bryce, 2006; Vorderer \& Bryant, 2012), this possibility is attractive not only for LGBT players. In roleplaying video games, $47.9 \%$ of players play avatars with the opposite gender (Vorderer \& Bryant, 2012). Male players do this more often - a female heroine was chosen five percent more by men (48.7\%) than a male character by women $(42.3 \%)$. Although Vorderer and Bryant do not account for the sexual orientation of players, their research illustrates the implicit possibilities of gameplay, no matter how heteronormative the content of the games is. Gaider (2013) also points out that in video games by Bioware, same-sex romances are played by $24 \%$ of players. 
If we take into account the game's affordances and possible uses, we arrive at a number of possible gaming situations that involve a LGBT player. First, if the game does not offer the option to play a gay character and the player is comfortable with this absence, he or she can accept playing as a heterosexual character and submit to the heteronormative discourse. If not, he or she can practice a "queer reading" of the character and interpret him or her as gay. Secondly, if the video game does allow for "queer performance" (implicitly or explicitly), players can utilize this possibility or not, regardless if they are gay or not. It has to be noted that if one does practice queer performance, he or she are also highly likely to interpret (or read) their own performance as queer, although such reading is no longer oppositional.

In this article, we will focus on queer reading and queer performance, both of which we consider elements of queer playing. We will then identify how these hypothetical uses of the game are realized as specific and situated strategies by LGBT players and under what conditions these strategies are applied. One of the basic questions of our research is the extent to which a player actually takes advantage of the potential for queer playing strategies, and what influences his or her decisions to do so.

\section{Research Goals}

So far, the few existing pieces of empirical research on queer- or LGBT-related topics and video games have been based on interviews or surveys with developers and activists (Shaw, 2009), or built on textual analyses of individual titles (Greer, 2013). We have instead chosen to focus on LGBT players' experiences as players of digital games, and specifically on their experiences playing the Dragon Age and Mass Effect series published by BioWare. ${ }^{5}$

Our inquiry was driven by two basic research questions: 1 . How are gaming practices of LGBT players related to their sexual identities? 2. How do LGBT players engage with role-playing games that include LGBT characters? Our aim was to identify queer playing strategies they use, and situate them in a broader context of the contemporary game culture.

\section{Methodology}

As our study is exploratory in nature, we opted for qualitative methodology and gathered our material by conducting interviews with LGBT players based in Prague, Czech Republic. The material was originally collected for one of the co-authors' Master's thesis project (Moravec, 2014). It has been completely recoded and re-interpreted for the present article.

We selected our interviewees among the members of the local LGBT community, based on personal recommendations and snowball sampling. The conditions for their inclusion was that a) they identified as LGBT, b) they were active players of digital games, c) they have extensively played at least one game in the Dragon Age or Mass Effect series. We believe that this selection method generated more valuable material than other possible methods, for example searching for interviewees within online communities dedicated to these games or to LGBT gaming. The latter would have necessarily involved self-selection, favoring players who already strongly identify as fans of BioWare games and outspoken "activist" players. ${ }^{6}$ Instead, our interviewees generally do not publicly express their fandom of the series or their experience of being LGBT players, and can be considered more "common" LGBT players, whose voices tend to be excluded from the public debate. Given that our respondents are Czech, the results of the study are not generalizable to LGBT minorities around the world. However, the Czech LGBT community is fairly similar to those in Western countries, and so is the prevalence and status of gaming (Asociace herního průmyslu, 2011).

We identified six players that met our requirements. As our research questions required deeper, contextualized interviews rather than a multitude of them, the number of interviews has proved sufficient to generate enough material for a qualitative analysis. All of our six interviewees were between 21 and 32 years old, and therefore fit into the age group which is most likely to play games - according to the 2011 survey conducted by the Game Industry Association of Czech and Slovak Republics, 36.2\% of Czech video game players are between 18 and 29 years old, which makes them the largest age cohort presented in the survey. (Asociace herního průmyslu, 2011). At the same time, our interviewees were mature enough to reflect on their gaming experiences in relationship to the formation of their sexual identities. Four of them have a higher education degree, two are high school graduates. Five of our interviewees are gay men (Tom, Jakub, Martin, Peter and Alex) and one is a lesbian woman (Eva). We did not find more lesbians to make the selection more balanced, but decided to include Eva, as her answers were not any more or less different from rest of the sample than the gay respondents' ones - save for one exception, which we will elaborate on. Respondents' names have been pseudonymized. We conducted all the 
interviews face to face in early 2014. Each interview consisted of about twenty questions and took 45-90 minutes. The interviews were conducted in Czech and translated into English by the authors of the article.

We asked each of the respondents to narrate their experience of the formation of their sexual identity and the role of media (including games) in this process, and to recount their gaming histories, including the notable games they have played. Then we proceeded to ask them about their experiences of playing as or relating to LGBT characters in BioWare games, and specifically about the elements of romance. Towards the end of the interviews, the respondents were asked to talk about the value the inclusion of LGBT content might hold for queer players and the LGBT community.

In the next stage, we performed qualitative content analysis of the transcripts. Our analysis combined theory-driven and inductive approaches. We followed the principles of analytic induction (Preissle, 2008) in order to create a typology from particular empirical evidence. Guided by our theoretical review, we identified those parts of the interviews which described player practices which could be considered queer. Using open coding (Benaquisto, 2008b), we established three major categories of strategies. We built tentative theoretical definitions of each of these categories and iterated on our analysis until the social practices observed adequately aligned with our definitions. Then we explored the relationships of these strategies to the rest of the collected material. We observed that the choice of a particular strategy is connected to contextual factors, such as the player's identity and his or her evaluation of the game's content. Therefore we undertook several rounds of focused coding (Benaquisto, 2008a) in order to extract common patterns of these connections. The following sections will start by explicating the contextual factors, before going on to discuss the particular categories of queer playing strategies.

\section{Results}

\section{A Gay Geek Does Not Belong Anywhere}

Although this work focuses primarily on queer playing strategies, these are inextricably linked to the question of the players' identities. All of our respondents identify themselves as players or gamers. ${ }^{7}$ They started to play at a very early age (before entering the school system, at the average age of 5 years). Some of them mention that they used to have high status among peers thanks to access to video games, but simultaneously admit that lately they have been feeling under social pressure from their families and their current peers because of their hobby. "I identify as a gamer. My family uses that word in a negative way, and some of my intellectual friends use it as derogatory word. But personally, I don't have a problem with that," Tom explains.

All interviewees started out by playing relatively simpler action games (platformers and first person shooters) and later on moved to narrative-driven games, mainly RPGs. While they take advantage of their escapist nature, they generally acknowledge that RPGs reflect on real-world issues. Peter describes them as video games with strong stories which comment on real-world problems. Tom adds: "It takes me away from the reality in which I live, but in a way it's still similar. I can find some metaphors for life in it."

These statements correspond to the notion that a virtual world can provide a safe space and an opportunity to experiment with different aspects of fantasies and (gender) identities. But while our interviewees enjoy playing RPGs, they all agree that the first games that allowed them homosexual interactions were The Sims (Maxis, 2000) and similar simulations of social life. The Sims games offer the possibility of entering both heterosexual and homosexual relationships, and have therefore been described as platforms for queer experiments (Consalvo, 2003). The titles in the series have been labeled as a girls' games (Gee \& Hayes, 2010; Wirman, 2011), but they also offer opportunities for the self-realization of LGBT players. As Alex says, "every gay person plays The Sims."

Their experimenting notwithstanding, none of the respondents saw video games as a tool that would help them in understanding their homosexual identity or with their coming out. "The Glee series helped me in coming out more than video games did, because everyone knew Glee, but only a few people knew some indie games," Martin explains. Only Peter admitted that the process of coming out influenced his strategies of playing. When he was 15 , he began to realize his homosexuality and for a period of time, he would play female characters.

In general, our respondents identify themselves as regular players and also as gays or lesbians, but they do not feel the need to connect these two identities. They do not reveal their sexual orientation in the gaming community, and none of them identifies himself or herself as a "gaymer". As Martin puts it: "It pisses me off when I'm playing with some guys who are nice and all, but then they ask things like what 
pussy I've fucked and where." However, he does not reveal himself as gay while playing. Peter also perceives the strong heteronormativity, perhaps even homophobia, of gamer communities: "Gamers are mostly children and men. Because this stereotype is so strong that nobody else wants to take on this identity. [...] And the industry supports it. In the Czech Republic, there are no openly gay guys who make games, and that's why people don't talk about it, and instead play games where you can kick someone's ass and then go on dates with some bitches."

Another player, Martin, confirms the feeling of alienation. Speaking of the gamer community, he says: "They are idiots. Every gamer thinks he's right, they are fighting about who is better, stronger. There is so much competition. I don't feel this in the gay community. [Gays] do talk about who's hot, but that's alright". Jakub, on the other hand, positions the source of alienation within the gay community: "I think it's because of the reality of gay online dating sites, because the alpha males on these sites are sportsmen, dancers, people who on principle don't play games. You can't function in this community unless you go to the swimming pool or the gym three times a week, if you don't have the perfect body. And that goes against the passion for PC games. In my opinion, video games are a forbidden topic in this community." Half of the respondents share a common feeling that they are standing on the edges of both subcultures, while not belonging to any of them. As Jakub puts it: "I think that a geek is doing just as badly inside the gay community as outside of it, perhaps even worse."

Our material therefore suggests that LGBT players see little connection between their LGBT identities and their player (or gamer) identities. As we will see in the following sections, this may make the adoption of queer playing strategies rather problematic.

\section{Reception of In-Game Sexuality: Macho Men and Girly Elves}

Most of our respondents do not see video games as places where they would seek out sexual themes. For Jakub, games are generally sterile and politically correct, and treat sexual themes as taboo. "Because of this, it is hard to perceive sexuality in games," he explains. The only exception is our lesbian respondent Eva, who is enthusiastic about sexuality in video games: "It's really cool to watch someone having sex with someone, it's superhot, because you've been playing this character for four hours [...]." Her feeling may stem from the fact that heteronormative portrayals of sexuality are intended for the male viewer, thus it might be easier for lesbians to assume the male gaze necessary to experience such pleasure.

Our interviewees have their reservations about the representation of queer characters that do appear in games. According to Jakub, this depiction is always negative. "You have to identify [the character] as homosexual. It's always the fag bartender or militant lesbians in suits." Three of our players have criticized the character of Zevran, the bisexual elf (and potential party member) in Dragon Age: Origins. Interviewees reason that elves are often portrayed as feminine and gentle characters, and this is why the developers picked an elf as a token homosexual. "They might have as well chosen a dwarf, but they didn't," says Tom. On the other hand, the interviewees do point out that video games stereotypically portray heterosexual characters as well. For Eva, games are mainly a man's world. "They are quite sexist [...]. All the women are hot, big boobs and butts [...], they're all slim and flexible. This is totally a hetero guy's stereotypical ideal of a fantasy lesbian."

Respondents agree that regarding sexuality, video games have different status than other media. As Alex puts it: "Movies are different, they're closely linked with sexuality. In video games, I can't think of a situation that would make me excited. I don't see it." Movies and TV series are still considered the media which can successfully speak about sexuality, homosexuality and queer relationships. Games are in comparison seen both as a medium which has less impact, as well as a product of an industry which lacks the will to be inclusive.

However, at least two respondents - Tom and Eva - do emphasize the potential of video games, especially because the movie experience is shorter, less intense and non-interactive. As Tom points out: "In a game, you live with the character and you're with him for a longer period of time, but the film experience is still stronger."

\section{Queer Playing: Strategies and Consequences}

All interviewees agree that they have attempted to play same-sex romances or gay characters many times. Analyzing the recollections of their gaming experiences, we can recognize three different strategies of queer playing: imaginative play, stylized performance and role-playing. While the first corresponds to 
the theoretical concept of queer reading, as developed by Greer (2013); the latter two strategies can be seen as two different kinds of queer performance.

Imaginative play. The first and the most common strategy for all interviewees is imaginative play. Imaginative play can be understood as an "oppositional" queer reading of a game, in which the player takes advantage of polysemy in order to adjust characters' sexualities in his or her own imagination. Interviewees tend to use this strategy in situations where the character is only implicitly heterosexual, but sometimes even in the cases of declaratively heterosexual characters. "When superheroes wear tight costumes, I read them as homosexuals. Sometimes it may not be explicit, but you think that developers wanted to say something," Tom explains. These hints can be recognized only by those who are looking for them and remain hidden for most players (a fictional relationship can, for example, be understood both as a same-sex romance and a "bromance"). Interviewees attribute the presence of this "invisible" homosexuality to the heteronormative and homophobic discourse. According to Tom, developers are generally afraid of the reaction of players: "LGBT romance is therefore hidden. You will find it - if you want."

Our respondents have mixed opinions on slash fiction ${ }^{8}$ and shipping ${ }^{9}$ - both of which can be considered textual manifestations of queer reading. Not all of them are willing to read slash. Peter outright refuses both gay shipping and slash, because "the characters should be as they are written."

Interestingly, our respondents seem to prefer imaginative play over other possible strategies, such as subversion of the gender system of the game. For example, none of the players has chosen to play a female character to achieve romance with a male companion or non-player character. The only exception is Peter, who was playing female characters during the process of his coming out, but when he started to play Dragon Age and Mass Effect games, he had already decided to return to male characters. Eva notes: "I didn't go so far as to play as a man. I want to be a woman, not a man. Tom adds: "In 95\% of cases I choose male characters. I can identify with them better." In terms of identification, the gender of an avatar thus matters to the player more than the avatar's sexual orientation, which indicates that the discursive power of gender tends to be stronger than desire for queer playing.

Stylized performance. The second strategy can be called stylized performance. In this case, the player deliberately performs as a queer character by marking the character with stereotypical signs of his or her sexuality. Martin, for example, dressed the player character, Commander Shepard, in pink, and therefore performed a stereotype in a demonstrative manner that can be related to the display of sexuality practiced at Pride Festivals. Peter did similar things, although in different games: "Sometimes, I made a pink tattoo in Final Fantasy XIV (Square Enix, 2005). Or I drove a pink car in Grand Theft Auto." This performative act can be understood as a declaration of one's own homosexuality, and at least a temporary adoption of the "gaymer" identity. In a similar sense, interviewees appreciate the character of Gay Tony from Grand Theft Auto IV (Rockstar North, 2008). Tony connects the very masculine sphere of organized crime and stereotypical depiction of homosexuality and uses his stylization (e.g. his pink suit) as an advantage.

Some of our gay interviewees create avatars that follow the stereotypical ideals of the heteronormative discourse; they make them very masculine and handsome. Martin, for example, enjoyed the pleasure of watching male characters. "He was not me. [...] I was not my hero, rather, I watched him." Tom chooses a similar strategy: "I used to undress male characters and I ran around with them." This situation can be explained by the fact that in relationship to the avatar, the processes of objectification and identification can occur simultaneously (Consalvo, 2003).

This strategy seems to be paradoxical. During stylized performance, interviewees use the same stereotypes (pink clothes, feminine voice) that they criticize in in-game portrayals of LGBT characters. This can, however, be explained by the difference in power relations. Performing stereotypes from a queer position can be interpreted as celebratory, while writing stereotypes from a heteronormative position is seen as oppressive.

While stylized performance seems not to be uncommon in queer playing of other genres, such as social simulations like The Sims or open-world game like Grand Theft Auto IV, it may be rarer in single-player role-playing games, which usually steer the player in the direction of dedicated role-playing. Players may also tend to avoid this strategy when playing online multiplayer games, in order to fit into the heteronormative community. Martin notes: "I don't want everyone to know that I am gay. I am, for example, in a guild of gay villains in DC Universe. Most of them have latex outfits, but I on the contrary styled myself as masculine and I wear black." 
Role-playing. The third queer playing strategy is the actual role-playing, a strategy which is most readily associated with BioWare titles and which involves a degree of identification with a queer character within a game's pre-designed narrative.

Role-playing as a gay or a lesbian can be related to the game's affordances and the player's knowledge of these affordances, but this relationship is in no way straightforward. As we mentioned above, the first two Mass Effect games did not contain same-sex romances featuring gay men, but any player who was roleplaying a gay Shepard had the option not to engage in heterosexual romances, and therefore "preserve" the character's sexuality. Peter, for instance, role-played as a gay Shepard throughout the whole series: "I was faithful to Kaidan. There was an unsaid love between them, so I did not play any other romances in the [third] game," he explains. Martin, on the other hand, had practiced heterosexual romances in the first two instalments of Mass Effect. His commander Shepard used to be very promiscuous - the player wanted his heterosexual hero to have "some fun". But after the possibility of gay romance had been introduced in the third instalment, he started to take it "more personally" - he stopped changing partners and identified with his gay character.

Perhaps unexpectedly, the interviewees' reaction to the opportunity of explicit queer playing tended to be rather lukewarm. In a way, they were surprised by the possibility of same-sex romance in Mass Effect 3. Both Jakub and Eva stress that they were not "used to" such opportunities and therefore were not looking for them. Some of the players expressed their desire to play through the game again and "for real", now that they knew that they could experience a gay romance. Martin, for example, wanted to start again and improve the ending of his romance and pick a different partner. "It was my first gay romance, I like this option. But seriously, I expected more than a date, wine and sex. I'd like it to be deeper."

Even after realizing this possibility, some players express little desire to investigate whether their character's potential romantic partner is gay or not. As Jakub puts it: "I can perceive the voice, the face. But I've related to the personality, not to the question of sexual orientation." Alex claims that he does not want to think of it during the playing: "The question of moral choices, for example, is more interesting than thinking about whether someone is gay or not."

All of our players agree that gameplay and story come first - not romance. Therefore, they tended to be more open to the gay romance with Anders in Dragon Age II, which was integral to the main storyline. As Peter explains: "It was so well written, it took my breath away. For me, this moment was extremely personal, which hadn't happened before. In Mass Effect, romance has no meaning, but this made homosexual romance a central part of the story, not just a side branch," explains Peter.

Our interviewees' approach to role-playing can be summed up by saying that they are players first, queer players second. They tend to role-play an LGBT character only when they are well aware of the fact that it is possible and that there is a romance option that would fit their player characters in terms of narrative. Their desire to play a gay character or engage in a same-sex romance is much greater when these are central to the story.

\section{Towards Emancipation and Inclusivity}

The inclusion of same-gender romances and LGBT content in general is welcomed as a plausible form of "moderate activism" by some interviewees. They suggest that games could help people in the coming out process by including side-stories featuring a gay character going through a similar experience; or that ingame same-sex romances can give LGBT people strength and courage. LGBT characters in games can also educate homophobic players. As Alex puts it: "It could be an ad for gays, because a guy can meet some faggots and find out they are cool." Peter remarks that the existence of queer romances show that there are not only queer characters, but also queer players that these were made to reflect, and therefore supports Gaider's (2013) point about diverse audiences.

At the same time, interviewees tend to be very cautious about the scale and intensity on which LGBT content should be included, so that the games do not to make "a big deal out of it". All respondents emphasize that it is not desirable to put too much emphasis on the representation of LGBT sexualities in video games. "I don't believe that gay should have a special status. Sexuality must not be what constitutes your identity. [...] We shouldn't want to constantly remind people that there is a different sexual orientation. I don't want to get to the other extreme," Jakub admits. Eva stresses that "it is still only sexual orientation and every person is different." 
They also feel skeptical about the effects of such efforts. Some are afraid that the inclusion of LGBT content may be just a cynical PR ploy; some are unsure whether a handful of queer characters in video games can change the status quo. The players find this unlikely given their understanding that video games are not a part of gay culture and that games with LGBT themes are played by only a negligible number of people.

Nevertheless, there is an agreement that homosexuality should be "done better" in video games. Homosexuality, like heterosexuality, should be an integral and well-written part of narrative. According to Alex, "it is better for the community to show homosexuality at full blast, as a part of the story, not as a hidden option". Peter bemoans the fact that the character of Cortez - a possible gay love interest in Mass Effect 3 - is effectively hidden from sight, "sitting somewhere, tucked away on the third floor in the armory."

All in all, the interviewees express cautious optimism about the contribution a higher degree of inclusivity could have for the LGBT community, while being concerned about the possible ghettoization of gay players, or even possible homophobic reactions triggered by "pushing too hard" for queer content.

\section{Conclusions and Discussion}

In the introduction, we warned against unfounded assumptions about LGBT audiences. The analysis has indeed shown that these players are not a homogeneous group that jubilantly accepts LGBT content in role-playing games. Even among LGBT players, queer performance (either stylized, or the performance of role-playing) may not be the default playing strategy. While players appreciate the inclusion of gay or lesbian characters and romances, and they have all, to some extent, played with or through them, this is usually not the reason for picking a particular character or even the game. Looking closely at the material, we have been able to discern relationships between the reasons not use queer strategies and the broader socio-cultural context.

Out of the three queer playing strategies we identified, imaginative play is the one that is most readily accepted by our interviewees. Its familiarity and acceptance may stem from the fact that it is not specific only to the medium of video games. It takes the least amount of physical effort and remains mostly in the private world of one's imagination. But when such imagination goes public in the form of slash fiction, its reception can be colored by the feeling that slash contradicts the content of the game.

The second strategy is stylized performance, through which players deliberately perform stereotypical depiction of gays (pink color or feminine voice) and thus deconstruct these cultural patterns. Once again, the interviewees feel more comfortable doing this in single-player games like Mass Effect than publicly in online multiplayer games.

The third strategy is role-playing of an LGBT character. While some have employed it, the players noted that sexuality was not an important variable for them, and they put much more emphasis on story and portrayal of the characters, and not on whether they are gay or not. They tend not to play a character of the opposite sex, contradictory to what Vorderer \& Bryant's research might suggest (Vorderer \& Bryant, 2012).

Our findings support Greer's claim that designers "who seek to allow gamers to 'play queer' - or merely to play as anything other than heterosexual" face complex challenges (Greer, 2013, p. 17). LGBT players' reluctance to play queerly can be partially ascribed to the fact that while playing games, they consider themselves "players" rather than "gay players". They accept the genre conventions and game design norms that are still very much determined by the heteronormative discourse. They have not learnt to look for LGBT content, or rather, they have learnt not to look for it in games. As self-proclaimed outsiders of video game culture, some of them might have even missed the ongoing public debate about these topics. They criticize "hidden" and "invisible" homosexuality, but when a gay character is made an integral part of the story in Dragon Age II, this is met with much more enthusiasm.

The relationship between (non-)queer playing and player identity seems to be quite significant. The interviewees see their gay identities and player identities as almost completely disjunct; they do not feel any need to associate the two, although they consider both of them important. This may be the reason why some of them do not seek sexuality in video games. For these players, games have not yet become a medium which could in any way help them with the (re)definition of their sexual identity. This is to some extent caused by the medium's aforementioned strong heteronormative tendencies, fortified by the overwhelming indifference of the game industry and by the hostility of some members of game 
communities towards the LGBT minority (Shaw, 2009). There is one exception - the player Peter, for whom the process of coming out was connected to a temporary change in gameplay strategies. His example may provide some support for Cassell and Jenkins' claim that games can help during the process of coming out (Cassell \& Jenkins, 2000).

BioWare's efforts to be inclusive were not met with unanimous excitement, but rather with moderate approval. Each LGBT player approached the BioWare titles differently. One dressed his Shepard in pink, another one played a heterosexual Commander. One was disappointed by the stereotypical gay elf in Dragon Age: Origins, yet another one, Alex, went full on with queer playing, recounting: "In Dragon Age, I just created a handsome guy and tried to hook up with somebody. I didn't communicate with women, I wanted them to be nothing more than my friends."

In general, the interviewees see the inclusion of gay characters both as an important step for the LGBT community and as a tool in the fight against homophobia. Echoing Shaw's (2009) conclusions, they agree that games have a lot of potential as outlets to express and understand one's sexuality, but this potential is still underutilized. We have also observed a certain discomfort about games becoming oversexualized and about them presenting homosexuality as something out of the ordinary. Inserting bits and pieces of LGBT content is seen as commendable, but a deeper integration of well-written non-stereotypical LGBT narratives could prove more valuable to the community.

This article is based on a small-scale qualitative research focusing on a mere subset of potential queer playing strategies, and we can therefore make no generalizations. On the other hand, its outcomes can lay foundations for further inquiry. One could undertake survey-based quantitative studies to learn about the prevalence of queer playing strategies or approaches to gaming in various regional or cultural contexts. This would be of use to both academia and the proponents of inclusiveness. Games scholarship would also benefit from qualitative, and later quantitative, research on how other groups of players, such as lesbians, transgender people or heterosexuals experience sexuality in video games and how their approaches to play are shaped by heteronormativity. All in all, the diversity of players, player communities, and player strategies - which this article has hinted at - promises ample possibilities for further research.

\section{Notes}

1. For example BioWare, Lionhead Studios, or Maxis in their series The Sims (Greer, 2013).

2. The concept of affordances originates in the disciplines of human-computer interaction (HCI) and design theory. According to Gaver (1991), affordances are "properties of the world that are compatible with and relevant for people's interactions" ( $p$. 79). In role-playing games, we might understand affordances as "the ways in which the player is able to express his or her wishes 'in role' as a player character in relationship to the game designer's conception of that role." (Greer, 2013, p. 7).

3. There are also other ways in which rule systems of games deal with gender. The game may entirely restrict the possibility of a queer reading by forcing the player character into a heterosexual relationship, or not differentiate between playing gay and playing straight (which is, to some extent, true of the game Fable). For more about the latter, see (Greer, 2013).

4. Although this love interest is an alien, her visual representation and voice acting suggest that she is female.

5. Interviews with players were conducted before the release of the third instalment in the Dragon Age franchise, 2014's Dragon Age: Inquisition, and therefore we do not discuss the game in this article.

6. While Shaw (2009) did interview players, they only constituted a minority of her sample; moreover, they had been recruited from "gaymer" online communities.

7. In English, the word player is used to describe a person who plays video games, and the word gamer is usually reserved for people who declaratively identify themselves as members of a wider gaming community or a gamer subculture. In the Czech language, there is no distinction between the words gamer and player. We therefore could not ask interviewees whether they identified as "gamers", but rather inquire about their relationships to gaming communities or culture. In the English translations of the interviews, we use the word which is most suitable in the particular context. For more about gamer identity, see (Shaw, 2010). 
8. Fan fiction describing sexual relationships between fictional characters of the same sex.

9. Changing gender identities of fictional characters in the audience's imagination or creative work.

\section{References}

Anthropy, A. (2012a). Dys4ia. Adobe Flash. Newgrounds.

Anthropy, A. (2012b). Rise of the videogame zinesters: How freaks, normals, amateurs, artists, dreamers, dropouts, queers, housewives, and people like you are taking back an art form. New York: Seven Stories Press.

Asociace herního průmyslu. (2011). Herní průmys/ v roce 2011[Gaming industry in 2011]. Praha:

Asociace herního průmyslu.

Benaquisto, L. (2008a). Codes and coding. In L. M. Given (Ed.), The Sage encyclopedia of qualitative research methods (pp. 85-88). Los Angeles, Calif: Sage Publications.

Benaquisto, L. (2008b). Open coding. In L. M. Given (Ed.), The Sage encyclopedia of qualitative research methods (pp. 581-582). Los Angeles, Calif: Sage Publications.

Benshoff, H. M., \& Griffin, S. (2004). Queer cinema: The film reader. Psychology Press.

Berger, A. A. (2002). Video games: A popular culture phenomenon. Transaction Publishers.

BioWare. (2005). Jade Empire. PC. 2K Games.

BioWare. (2007). Mass Effect. XBox 360. Microsoft Game Studios.

BioWare. (2009). Dragon Age: Origins. PC. Electronic Arts.

BioWare. (2010). Mass Effect 2. PC. Electronic Arts.

BioWare. (2011). Dragon Age II. PC. Electronic Arts.

BioWare. (2012). Mass Effect 3. PC. Electronic Arts.

Butler, J. (1990). Gender trouble: Feminism and the subversion of identity. London: Routledge.

Cassell, J., \& Jenkins, H. (2000). From Barbie to Mortal Kombat: Gender and computer games.

Cambridge, MA: MIT Press.

Connell, R. W. (2005). Hegemonic masculinity: Rethinking the concept. Gender \& Society, 19, 829-859. http://dx.doi.org/10.1177/0891243205278639

Consalvo, M. (2003). Hot dates and fairy tales romances: Studying sexuality in video games. In B. Perron \& M. J. P. Wolf (Eds.), The video game theory reader (pp. 171-194). London: Routledge.

Gaynor, S. (2013). Gone Home. PC. Fullbright.

Gaider, D. (2013). Sexism and sexuality in games. [Video]. Retrieved from

http://www.gamasutra.com/view/news/194571/Video_Sexism_and_sexu

Gaver, W. W. (1991). Technology affordances. In Proceedings of the SIGCHI Conference on Human Factors in Computing Systems (pp. 79-84). New York, NY, USA: ACM.

http://dx.doi.org/10.1145/108844.108856

Gee, J. P., \& Hayes, E. R. (2010). Women and gaming: The Sims and 21st century learning. New York: Palgrave Macmillan. 
Greer, S. (2013). Playing queer: Affordances for sexuality in Fable and Dragon Age. Journal of Gaming \& Virtual Worlds, 5, 3-21. http://dx.doi.org/10.1386/jgvw.5.1.3_1

Hall, S. (1980). Encoding/decoding. In S. Hall, D. Hobson, A. Lowe, \& P. Willis (Eds.), Culture, media, language (pp. 117-127). London: Routledge.

Halperin, D. M. (1997). Saint Foucault: Towards a gay hagiography. OUP USA.

Haraway, D. (2013). Simians, cyborgs, and women: The reinvention of nature. London: Routledge.

IGDA. (2014). Developer satisfaction survey 2014: Summary report. International Game Developers Assocation. Retrieved from www.igda.org/resource/collection/9215B88F-2AA3-4471-B44D-

B5D58FF25DC7/IGDA_DSS_2014-Summary_Report.pdf

Jagose, A. (1996). Queer theory: An introduction. New York City: New York University Press.

Kennedy, H. (2002). Lara Croft: Feminist icon or cyberbimbo? Game Studies, 2(2). Retrieved from http://www.gamestudies.org/0202/kennedy/

Klevjer, R. (2006). What is the avatar? Fiction and embodiment in avatar-based singleplayer computer games (Doctoral dissertation thesis). Bergen: University of Bergen.

Maxis. (2000). The Sims. Electronic Arts.

Moravec, O. (2014). Vývoj reprezentace LGBT menšiny v počitačových príběhových RPG hrách a přijímání homosexuální tematiky hráči a herními vývojáři [Progress in the representation of the LGBT minority in narrative RPG video games and the acceptance of queer topics by gamers and game developers]

(Master's thesis). Charles University in Prague, Prague.

Mulvey, L. (1989). Visual and other pleasures. New York: Macmillan.

Nintendo. (1981). Donkey Kong. Nintendo.

Preissle, J. (2008). Analytic induction. In L. M. Given (Ed.), The Sage encyclopedia of qualitative research methods (pp 15-16). Los Angeles, Calif: Sage Publications.

Reich, J. L. (1992). Genderfuck: The law of the dildo. Discourse, 15(1), 112-127.

Rich, A. C. (2004). Reflections on "Compulsory Heterosexuality." Journal of Women's History, 16(1), 911. http://dx.doi.org/10.1353/jowh.2004.0033

Rockstar North. (2008). Grand Theft Auto IV. Rockstar Games.

Rutter, J., \& Bryce, J. (2006). Understanding digital games. London: SAGE.

Shaw, A. (2009). Putting the gay in games: Cultural production and GLBT content in video games. Games and Culture, 4, 228-253. http://dx.doi.org/10.1177/1555412009339729

Shaw, A. (2010). What is video game culture? Cultural studies and game studies. Games and Culture, 5, 403-424. http://dx.doi.org/10.1177/1555412009360414

Sliwinski, A. (2007, April 11). Gay gamer survey results with large hetero inclusion [Web log comment]. Retrieved from http://www.engadget.com/2007/02/26/gay-gamer-survey-results-with-large-heteroinclusion/

Square Enix. (2005). Final Fantasy XIV. Square Enix.

Sullivan, N. (2003). A critical introduction to queer theory. Edinburgh University Press. 
Taylor, T. L. (2002). Living digitally: Embodiment in virtual worlds. In R. Schroeder (Ed.), The social life of avatars: Presence and interaction in shared virtual environments (pp. 40-62). London, New York:

Springer.

Vorderer, P., \& Bryant, J. (2012). Playing video games: Motives, responses, and consequences. London: Routledge.

Wirman, H. E. (2011). Playing The Sims 2: Constructing and negotiating woman computer game player identities through the practice of skinning (Doctoral dissertation thesis). Bristol: University of the West of England.

\section{Correspondence to:}

Jaroslav Švelch

Faculty of Social Sciences

Smetanovo nabrezi 6

11001 Praha 1

Czech Republic

Email: svelch(at)fsv.cuni.cz

\section{About authors}

Tereza Krobová is a Ph.D. candidate at Charles University in Prague. Her research focuses on issues related to gender and representation in the media, especially in video games. She works as an editor of online news outlet and cooperates with NGOs that deal with human rights and gender mainstreaming.

Ondřej Moravec is a media studies graduate from Charles University in Prague. He has also studied screenwriting at the Faculty of Performing Arts in Prague. He worked in Czech public service television, and now he works as a film festival programmer. His main research interest is combining film and game techniques in audiovisual works.

Jaroslav Švelch is a lecturer and researcher at the Charles University in Prague's Faculty of Social Sciences. He was a Fulbright visiting researcher at MIT's GAMBIT game lab from 2007-8 and a Ph.D. intern at Microsoft Research New England in 2012. His work focuses on local histories of computer games, social uses of digital technologies, humor in virtual spaces, online language management, and the concepts of monstrosity and adversity in games. 